\title{
A linguagem visual e a percepção: um estudo de caso em crianças
}

Eloah Maria Oliveira Acauan (Currículo Lattes) João Eduardo Chagas Sobral (Currículo Lattes)

\section{INTRODUÇÃO}

O design atua, enquanto linguagem visual, com um conjunto de orientações acerca do uso e do desenvolvimento de elementos imagéticos em suas mais diferentes configurações. Em contrapartida, encontra-se o processo de visualização. Assim como todo o processo de aprendizagem, a percepção visual é dependente do contexto sóciocultural ao qual está inserida. São os agentes culturais os maiores modificadores da percepção e, portanto, da linguagem visual. A partir disso, alguns questionamentos desenvolvem-se: serão efetivas as orientações da linguagem visual criadas em uma época e aplicadas em outra? Será a percepção orientada pelas teorias visuais 
aplicadas ou pelos agentes culturais? Tais teorias respeitam aspectos sociais e culturais em um processo dinâmico? Ou, ainda, até que ponto as orientações transmitidas dentro do campo do design, em relação à visualidade, são efetivas com o passar dos anos?

O presente artigo busca algumas possíveis respostas ao analisar, por meio da pesquisa experimental, aspectos da linguagem visual em crianças menores de 5 anos. Essa análise utiliza, como elemento visual analisado, a fotografia.

A escolha pela fotografia caracteriza-se por sua natureza muito próxima ao referente, diferentemente de outras configurações visuais como o desenho ou a representação gráfica (dependentes e extremamente variáveis conforme época e região). Essa proximidade tende a facilitar o reconhecimento dos processos perceptíveis.

Entretanto, sendo a fotografia um produto cultural e o indivíduo fruto das relações com o meio (VYGOTSKY, 2010) como buscar os processos perceptivos mais pessoais, ainda não moldados pelo contexto cultural? A criança, em suas relações iniciais com a sociedade e os processos perceptivos, representa um usuário em potencial.

A linguagem visual, para a criança, exerce forte representatividade nas relações com o mundo que a cerca e, embora as pesquisas a respeito do processo de desenvolvimento da inteligência no indivíduo sejam bastante exploradas, pouco se conectam com as relações da imagem e da visualidade.

É por meio do olhar analítico de Vygotsky (2010) que o aprofundamento das relações psicológicas estabelecidas na criança e suas particularidades enquanto indivíduo ficam evidentes. As definições de método e de recorte, relacionados à idade das crianças estudadas, também derivam das observações do autor. 
Durante o processo de estruturação do objeto de estudo tornou-se evidente o enorme universo abordado pela visualidade, impondo, assim, à pesquisa um necessário e expressivo recorte de estudo. A fim de promover reflexões mais aprofundadas acerca do objeto de estudo julgou-se adequado centrar a investigação em dois teóricos consagrados por suas contribuições na área da linguagem visual, quais sejam, Rudolf Arnheim e Donis A. Dondis.

Arnheim (2013) volta-se aos processos de percepção da forma e da linguagem visual relacionados à psicologia da Gestalt. Donis, por sua vez, orienta sua pesquisa a partir da necessidade do desenvolvimento de um alfabetismo visual, em especial após o advento da fotografia, desenvolvimento da câmera e seus desdobramentos.

O presente estudo, portanto, volta-se ao breve relato da pesquisa experimental aplicada e à discussão dos resultados obtidos durante o processo de pesquisa, não julgando apropriado adentrar as bases teóricas ou decisões metodológicas. Apresentando, portanto, apenas duas subdivisões: (I) a coleta de dados e (II) as análises.

\section{A COLETA DE DADOS}

A coleta de dados foi estruturada a partir do desenvolvimento do instrumento de pesquisa ${ }^{1}$ e das decisões que orientaram o processo metodológico. É importante ressaltar que a pesquisa aplicada apresenta natureza experimental, embasada nos processos

\footnotetext{
${ }^{1}$ As especificidades acerca do desenvolvimento do instrumento de pesquisa e definições sobre o processo metodológico estão constantes na macropesquisa da qual desdobra-se este estudo, "As percepções do olhar: uma análise experimental da linguagem fotográfica em crianças".
} 
de investigação de Vygotsky e adaptados por meio do design às necessidades do objeto de pesquisa aqui relatado.

Os recortes das teorias visuais de Arnheim e Dondis apresentam sua maior contribuição para a construção dos parâmetros de análise e, por fim, as reflexões de Vygotsky orientaram a escolha da amostra ${ }^{2}$ e suas especificidades.

Nesta pesquisa busca-se desvelar relações estabelecidas entre o indivíduo e a percepção visual em um contexto de menor influência social e por consequência também dos processos visuais prémoldados culturalmente; por esse motivo, selecionou-se crianças em fase pré-escolar como objeto, considerando nessa decisão a premissa de Vygotsky (1998), que destaca que em um experimento que exige a compreensão da orientação oral expressa pelo pesquisador e a tomada de decisão diante de uma situação-problema não pode ser efetuada por indivíduos não possuidores de maturidade fisiológica necessária a essas operações. Portanto, acredita-se que a intersecção entre a menor influência social possível, inclusive da cultura midiática ${ }^{3}$, e a capacidade de estabelecer conexões lógicas que viabilizem o experimento ocorrem no período piagetiano chamado Pré-Operatório. Por se tratar de um estudo de caráter qualitativo, julga-se mais apropriado restringir o grupo estudado a crianças entre 2 e 3 anos de idade.

\section{O EXPERIMENTO}

O experimento consistia em uma bateria de sete escolhas relacionadas a alterações de seis elementos da linguagem visual:

\footnotetext{
${ }^{2}$ Aceita-se como amostra a mesma definição desenvolvida na macropesquisa: 12 crianças, de ambos os sexos, frequentadoras de Centros de Educação Infantil na cidade de Joinville, com idades de 2 a 3 anos.

${ }^{3}$ Considera-se, para este estudo, a cultura midiática como um grande núcleo da influência de imagens produzidas com fins psicológicos de orientação comportamental.
} 
referente (objeto representado), cor, nitidez, enquadramento (localização do objeto dentro do quadro da imagem), fotometria (relação da iluminação da imagem), ponto de vista (ângulo de visualização do objeto) e relação parte/todo (quanto do objeto era representado na imagem). Tais elementos foram obtidos por meio do cruzamento das teorias de Dondis (1997) e Arnheim (2013). Cada grupo apresenta cinco variáveis do mesmo elemento, apresentado referentes reais ${ }^{4}$ representados fotograficamente (por meio de fotografias).

Cada escolha, portanto, correspondia a um grupo de cinco fotografias apresentadas à criança em um único suporte, distribuídas de forma a gerar a menor influência possível no processo de escolha. O suporte tinha o formato circular por, seguindo a teoria da Gestalt, gerar continuidade e não indicar início e/ou fim, minimizando interferências no processo perceptivo.

A primeira escolha corresponde ao referente, já que é necessário estabelecer um vínculo entre a criança e o elemento observado para que não haja perda de interesse durante o processo de pesquisa. Da mesma forma que Vygotsky (2010) relaciona a experiência com o brinquedo como o meio para satisfazer as necessidades imediatas de uma criança pequena, a escolha do referente da fotografia permite à criança satisfazer algum desejo. Essa primeira escolha influencia os outros seis grupos de escolha. Os referentes oferecidos ao indivíduo são a bola, o gato, a colher, a mulher e um elemento da cultura midiática popular (Galinha Pintadinha), os referentes são apresentados, respectivamente, na Figura 1 a seguir:

\footnotetext{
${ }^{4}$ Julga-se mais adequada a utilização de um referente ao real pela relação denotativa e mais próxima à visualização "natural" do mundo, estabelecida pelo sentido da visão.
} 
Figura 1 - Referentes apresentados à criança na primeira etapa
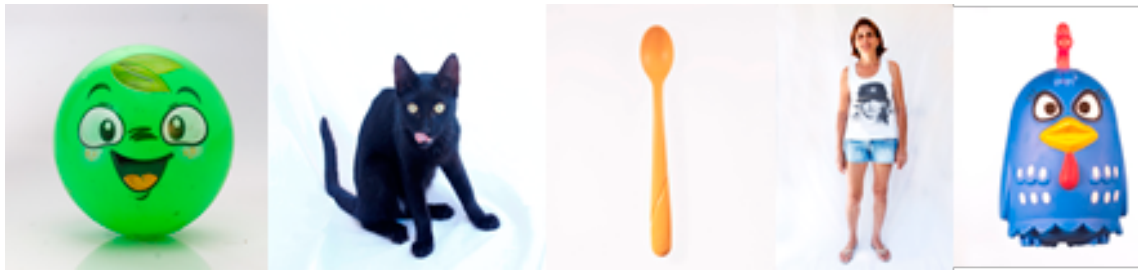

Fonte: primária

A segunda escolha, realizada pela criança, se refere a cor e não apresenta influência nos outros cinco grupos. Essa escolha contém apenas duas variáveis: a presença ou não da cor na imagem. As opções propostas às crianças apresentam como resultado uma sequência de sete escolhas.

As fotografias usadas no experimento foram apresentadas no formato impresso e reveladas em papel fotográfico, a fim de preservar seu caráter de realidade, bem como a qualidade da imagem; foram dispostas sobre suporte rígido redondo, conforme Figura 2 a seguir, e no formato $10 \times 15 \mathrm{~cm}^{5}$. Em pró da unidade imagética do experimento, optou-se por desenvolver as fotografias em estúdio, especificamente para a pesquisa, evitando assim o uso de imagens de bancos de dados ou internet.

\footnotetext{
${ }^{5}$ A escolha do tamanho da fotografia impressa se deu seguindo a orientação de um material grande o suficiente para que os detalhes sejam identificados, mas não tão grande a ponto de resultar em um grupo (disco com cinco fotografias) grande demais para sua completa visualização pela criança.
} 
Figura 2 - Disco utilizado como instrumento de pesquisa

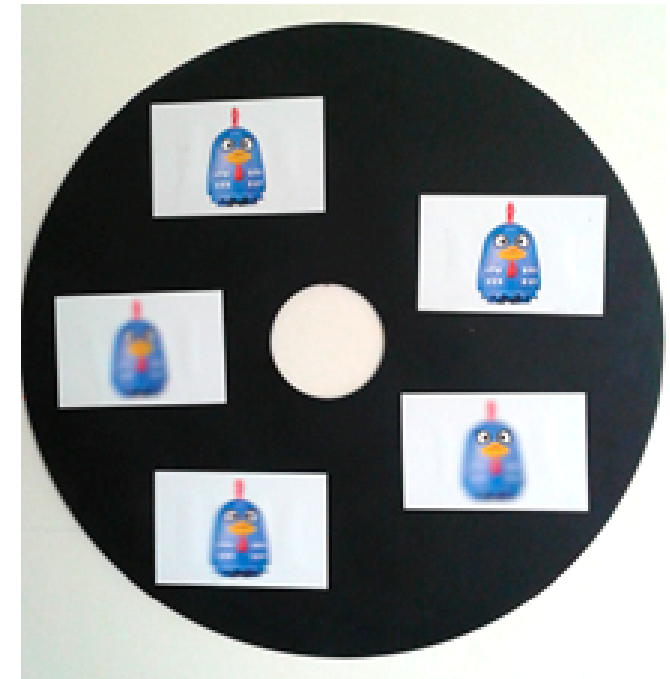

Fonte: primária

Optou-se em manter como fator condicionante à neutralidade do experimento a utilização do mesmo referente ao real em todas as fotografias. Já em relação à linguagem fotográfica, julga-se mais apropriado trabalhar um elemento a cada escolha, a fim de não prejudicar a análise e o processo de seleção desenvolvido. Tal qual a equipe de Vygotsky (1998), confronta-se a criança de 2 a 3 anos com a tarefa de escolha de uma das fotografias do grupo: o processo gradual de escolha, com a apresentação dos elementos separadamente e dependentes da escolha anterior, representa o equivalente caminho evolutivo dentro do processo da visualidade ${ }^{6}$.

Éimportante ressaltar que o tempo de aplicação do experimento foi parametrizado de acordo com a capacidade do público em reter a atenção a uma única tarefa. Por meio do grupo-teste percebeu-

${ }^{6}$ Esse caminho evolutivo é pautado no processo de desenvolvimento de uma imagem: referente, cor, ângulo, nitidez, enquadramento, luminosidade e quantidade visível do asunto. 
se a necessidade de limitar a duração de todo o experimento a 15 min de duração, tempos superiores cansavam o indivíduo e traziam resultados inseguros, já que era necessária uma retomada do processo de escolha.

Por tratar-se de uma pesquisa aplicada com seres humanos, foi submetida e aprovada pelo comitê de ética. O processo de pesquisa foi dividido em três dias de aplicação. No primeiro, desenvolveu-se o grupo-teste - constituído por 5 crianças, com idades entre 2 e 4 anos, de ambos os sexos e de turmas diferentes. $O$ grupo de teste identificou a necessidade de ajustes no processo metodológico.

Para a análise dos resultados, as considerações relevantes e escolhas desenvolvidas pelas crianças foram anotadas ao fim de cada etapa. Além disso, viu-se a necessidade da gravação do experimento em vídeo, já que o processo de escolha em crianças, evidencia Vygotsky (2010), está orientado pelo movimento e não só pelo resultado. Julgou-se ainda relevante a presença de um dos pais ou da professora, a fim de tranquilizar a criança e permitir o desenvolvimento da coleta de dados.

\section{OS PARÂMETROS E AS ANÁLISES}

Para o desenvolvimento da fase de análise dos dados coletados foram estabelecidos o uso de oito parâmetros ${ }^{7}$. No entanto, por tratarse do relato de uma parte da macropesquisa, julga-se apropriado apresentar apenas cinco destes. Os oito critérios utilizados foram (I) meio social, (II) cultura midiática, (III) objeto fotográfico, (IV) limites físicos, (V) contraste, (VI) preferência da cor, (VII) relação da

\footnotetext{
${ }^{7}$ Tais critérios correspondem a indicadores oriundos dos conteúdos teóricos levantados a partir das reflexões de Dondis (1997) e Arnheim (2013).
} 
tridimensionalidade e (VIII) percepção da nitidez. Os parâmetros reportados neste artigo são:

\section{Objeto fotográfico}

Observou-se com o experimento que a percepção do objeto fotográfico sofreu alterações durante a bateria de escolhas em 33,33\% das crianças estudadas.

Em alguns casos, a criança percebia ora o que estava representado na fotografia (referente), ora o conjunto de elementos visuais que a compunha. No segundo caso, a criança costumava descrever o elemento visual que lhe chamava atenção: "essa escura", "essa cinza", "essa grandona".

Outro fato interessante diz respeito à memória: quando o referente era identificado, e não suas características visuais, a atenção da criança volta-se aos processos subjetivos que esse referente despertava, com base na sua experiência. Por exemplo, numa das escolhas do referente gato a criança não visualizou as variações de nitidez apresentadas pela etapa, mas o gato muito parecido com o seu animal de estimação. A fotografia, nesse caso, corresponde à descrição de Dubois (1993) do 'espelho do real' e é por meio da sua forte semelhança com o objeto que a criança confunde a representação com o objeto.

Ainda em relação à experiência de vida, fatores como idade e personalidade mostraram-se relevantes e fortes moldadores da percepção. Indivíduos com idade próxima a 25 meses não demonstravam ter a capacidade de identificar alterações nos elementos visuais, as opções apresentadas no experimento representavam cinco formas diferentes do mesmo referente, tornando o processo de colagem do adesivo mais interessante que o processo de análise da linguagem visual. Talvez esse fato possa 
ser explicado pelo início do raciocínio técnico nessa fase citado por Vygotsky (1998): criança está no princípio do desenvolvimento da inteligência e da resolução de problemas.

Já em relação à personalidade, crianças com traços de hiperatividade tendiam a trocar os referentes no meio do processo de escolha, mas sem ignorar as alterações da linguagem visual. Ou seja, elas desenvolviam a análise dos elementos visuais sem, necessariamente, dependerem da visualização do mesmo referente. O processo de comparação de diferenças parecia mais fácil e dinâmico.

Deve-se considerar, ainda, que a percepção do referente pode se dar a partir da percepção da cor e da configuração da fotografia apresentada. Se a configuração, como cita Arnheim (2013), favorece a percepção do referente como um todo e não como um conjunto de elementos, o referente deve ficar mais aparente. A percepção da linguagem visual se dá caso a apresentação do referente (escolha do ângulo, enquadramento, plano, relação figura/fundo e contraste) ou sua própria configuração (cor e forma) apresentem formulação que prioriza a segregação do objeto em elementos. Entretanto, ainda é o indivíduo, dentro das suas funções psíquicas influenciadas pela sua bagagem, que determina a prioridade de percepção identificando a fotografia (elementos visuais) ou objeto (referente).

\section{Limites físicos}

Grande parte das orientações de linguagem fotográfica observa os limites físicos dos objetos, sua relação espacial e o próprio limite do quadro fotográfico. Todos os elementos e variações da composição partem do quadro e seu limite como base para qualquer desenvolvimento visual. Considerando ainda que cada etapa relacionava um grupo de fotografias e, para tal, constituía limites 
físicos para a percepção do grupo, busca-se compreender de que forma as crianças percebiam e interpretavam esses limites. Algumas crianças ao colar o adesivo o faziam em cima do referente. Outras, dentro dos limites físicos da fotografia, mas fora deste.

Para as que colavam o adesivo fora da fotografia, houve percepção dos seus limites físicos como algo que não poderia ser interferido, como um quadro em uma parede. $O$ suporte, nesse caso, representava área de livre interferência.

Enquadramentos diferenciados, com concentração do assunto em um dos terços (16,66\% das escolhas) ou no ponto de interesse $(41,66 \%)$ podem indicar uma preferência pelo dinamismo, movimento e minimalismo. Dentro da fotografia, esses enquadramentos são aplicados a fotografias mais atraentes, diferenciadas e que necessitem da ênfase em alguns pontos da imagem.

Já o enquadramento central do assunto, compatível com a estabilidade no centro do esqueleto estrutural de Arnheim (2013), foi a preferência identificada em apenas $25 \%$ das opções.

\section{Contraste}

O contraste, em uma fotografia, é constituído pela diferença entre o conjunto de altas luzes e pretos absolutos; quanto maior essa diferença, maior torna-se o contraste. Tudo, nesse caso, é dependente da luz incidente no objeto fotografado. A tonalidade de uma imagem, sua claridade, saturação ou alterações de cor são provocadas pela iluminação que recebem. Tais características apresentam-se como pessoais e mutáveis, variando de acordo com o momento e a bagagem cultural do indivíduo que as recebe.

A fotografia apresenta um norteador central, com cor, tom, fotometria e contrastes baseados no cinza médio 18\%. Aplica-se, aqui, o mesmo princípio do tom de Dondis (1997): é a relação com 
o objeto próximo, em uma imagem, que define se este é claro ou escuro. Naturalmente, um indivíduo pode concordar ou discordar dessa estimativa, optando por imagens supersaturadas, altos contrastes ou subexposições.

Apenas $25 \%$ da população estudada preferiu a fotometria pautado no cinza médio $18 \%$. Ou seja, pela teoria visual, apenas $25 \%$ teriam percepção dita adequada.

Entretanto, devem ser considerados aqui fatores extras, como acuidade visual e saúde das células responsáveis pela captação da luz e cor (cones e bastonetes). As crianças de menor idade oscilaram entre fotometria ideal (contraste médio) e supersaturado (baixo contraste para o claro). Uma das possíveis inferências é a imaturidade do globo ocular e, portanto, de suas células. Pode haver uma necessidade de maior incidência de luz para visualizar a mesma imagem.

Já os 33,33\% que optaram pela imagem subexposta podem tê-la feito em vista do aumento de pretos na imagem e, consequentemente, de contornos mais fortes na imagem. A fase dos 2 aos 3 anos é marcada pela iniciação nas artes da pintura, desenho e escrita, todas apresentando o traço bem definido.

Uma explicação possível para os $16,66 \%$ (duas crianças) que optaram pela fotografia saturada e os $8,33 \%$ (uma criança) pela contrastada pode residir no fato de ambas valorizarem a cor, aumentarem o contraste, valorizarem os níveis de preto e definirem os limites dos componentes do objeto e das cores. É relevante considerar que a pintura, nessa fase, é caracterizada pelo uso das cores primárias e puras (sem misturas com preto e branco), pelos contornos pretos e pelos fortes limites entre uma cor e outra. 


\section{Preferência da cor}

A visualização da cor, em uma imagem ou cena, corresponde ao primeiro elemento percebido. Como se trata de um processo psicológico torna-se pessoal e mutável: cada indivíduo enxergará uma determinada cor de forma diferenciada.

Dessa forma, a segunda etapa do experimento consistia na opção pela presença ou ausência de cor no referente escolhido. Apenas $16,66 \%$ optou pela ausência de cor conscientemente, muitas alteravam suas escolhas após visualizarem o referente colorido. Podese, nesses casos, afirmar que a opção pelo colorido pode indicar a necessidade de adequar a fotografia ao seu referente, uma vez que o mundo é percebido em cores. O uso do preto e branco, dentro dos conceitos visuais aplicados à imagem, indica aplicação de emoções e poesia à imagem, conceitos complexos para crianças nessa faixa etária.

Considera-se que, se as fotografias indicassem gravuras, desenhos ou imagens não referentes ao real, a escolha pelo colorido envolveria mais fatores. Por exemplo, se a criança gostasse da cor vermelha e lhe fosse apresentada uma imagem de uma bola vermelha, esta seria escolhida pela sua relação emocional com a cor. Já objetos reais representados de formas menos artísticas, como a fotografia, promovem escolhas pautadas na experiência: uma maçã pode ser verde ou vermelha, mas não azul. Dessa forma, Dubois (1993) relaciona a fotografia ao real, portanto considera-se plausível dizer que a preferência pelo colorido, em $75 \%$ das escolhas, deriva da relação referente/fotografia.

\section{Relação da tridimensionalidade}

Ao organizar as escolhas relacionadas ao ângulo de observação e o quanto do objeto se visualiza, buscava-se responder ao 
questionamento: será a criança de dois a três anos capaz de identificar esta imagem mesmo incompleta? Ou será esse processo construído culturalmente e, portanto, dependente da sua experiência social e reforçada com a idade?

Em relação ao ângulo de visualização, a maior parte das respostas acompanhou o processo lógico de visualização de objetos e as teorias visuais: frontal e ocupando todo o quadro da imagem. Contudo, obtiveram-se respostas variadas que, embora centradas no processo lógico, também indicavam a busca de ângulos inusitados. Estimava-se que as respostas seriam condizentes com o tradicionalmente visualizado pela criança em seu dia a dia: pessoas adultas vistas de baixo para cima; objetos pequenos, como a colher, de todos os lado; e animais pequenos de cima para baixo.

Entretanto, 50\% optou pelo ângulo inferior (de baixo para cima) em objetos pequenos e manipuláveis, como a colher, a bola e o gato. Tal dado indica uma preferência mais dinâmica e criativa do ângulo de visualização. Deve-se considerar a possibilidade de tal escolha ter sido influenciada pela pouca altura da criança em relação ao mundo natural: poucas são as coisas (pessoas, objetos e paisagens) não vistas em ângulo inferior. Talvez torne-se, nessa fase, mais natural a busca por esse ângulo. Os referentes gato e Galinha Pintadinha podem ter sido selecionados em sua visualização frontal por conta da perfeita aparência de seus olhos.

As escolhas de ângulos pouco usuais podem ser explicadas pelo despertar de emoções como curiosidade e diversão, dando caráter de brincadeira à imagem.

Em relação ao plano, 33,33\% escolheu o plano geral, um forte indicativo da preferência de percepção pelo objeto em sua representação mais informativa. Assim como as escolhas do plano geral aplicado ao gato e a colher permitem total visualização de seus elementos e proporções. 
Ainda em relação ao plano aplicado, as respostas enquadraram pelo menos $75 \%$ do objeto. A capacidade de completar objetos a partir de partes, ponto observado na etapa sete, é a premissa da Lei de Continuidade da Gestalt, bastante aplicada no universo da fotografia e do Design.

Estimava-se que essa concretização da totalidade da imagem não fosse possível nessa faixa etária. Entretanto, 25\% das respostas indicaram planos mais fechados, representando apenas $30 \%$ do referente. Sendo o plano detalhe indicado para a visualização da Galinha Pintadinha e o primeiro plano aplicado à bola e ao gato. Considera-se a possibilidade de tais escolhas terem sido desenvolvidas com base apenas na valorização dos detalhes de tais referentes.

\section{Percepção da nitidez}

A nitidez de um objeto corresponde a um dos elementos mais importantes para sua visualização. Esse é um dos elementos visuais mais relevantes para as teorias visuais: normalmente é a nitidez que permite a identificação do que está sendo representado. Entretanto, esse elemento é subjetivo e pode apresentar aplicações diferenciadas de acordo com a área visual e a época em que está inserido. Entre as respostas, 58,33\% correspondem a escolhas relacionadas aos graus alto e suficiente de nitidez. Mesmo ruídos na imagem podem representar, para a criança, nitidez suficiente para interpretar qual objeto está representado, 25\% apresentam essa escolha. Três crianças (25\%) efetuaram essa escolha e outras cinco (33,33\%) optaram pela referência padrão da teoria visual: nítido.

Apenas 33,3\% escolheram as imagens totalmente nítidas, contrariando boa parte das orientações das teorias visuais praticadas atualmente. Nos casos de escolha pelo desfoque é necessário considerar que a configuração do referente pode influenciar a 
escolha. Por exemplo, uma bola ainda é uma bola mesmo desfocada. Assim como imagens com grande grau de contraste entre figura/ fundo.

Não houve preferências pelo desfoque seletivo, talvez ocasionado pela pouca diferença entre o nítido, sendo necessárias acuidade visual e percepção dos detalhes bem desenvolvidas. Ou ainda, sua não ocorrência pode ser justificada pela simples falta de interesse.

\section{CONSIDERAÇÕES FINAIS}

Como parte integrante de uma macropesquisa, o presente estudo buscou analisar, partindo de um recorte específico, o grau de influência, ou a validade, das teorias visuais nos processos de percepção visual. Durante o processo de pesquisa, especialmente na análise dos dados, diversas surpresas e informações contrárias às expectativas teóricas estudadas foram apresentadas.

Tal qual a interpretação de um texto, a análise das possibilidades de leitura da linguagem visual deve ser exercitada e compreendida. 0 mundo real, uma fotografia, um vídeo, uma pintura ou uma gravura diferem de um texto apenas pela natureza de suas informações e, embora o indivíduo consuma um maior número de informações visuais, em comparação àquelas textuais, as primeiras pouco são discutidas e exploradas.

Embora a pesquisa desenvolvida tenha sido apresentada de forma resumida neste artigo, foi possível observar que o processo de decisões que levaram à configuração final do experimento e seus elementos foi um empreendimento delicado e minucioso. Cada escolha, fosse do mecanismo de aplicação ou do suporte e da cor usada, foi exaustivamente avaliada e parametrizada pelo objeto de 
investigação, suas características e as especificidades da população amostra.

Embora a filosofia de Dondis (1997) aponte para um alfabetismo visual e apresente passos para o seu exercício, e tenha sido parte constante da base teórica, a prática revela outros direcionamentos. O experimento desenvolvido nesta pesquisa revelou uma hipótese não apresentada por Dondis: o processo de percepção da linguagem visual é muito mais elaborada que a simples segregação de elementos, é um processo complexo e dependente do contexto cultural em que o receptor está inserido.

A influência do meio social nos processos psicológicos da criança mostrou-se imediata e, muitas vezes, determinante da sua abrangência. A experiência, nesse caso relacionada à idade, também representou um forte modificador da capacidade perceptiva da criança: a experiência e o amadurecimento biológico permitiram conexões e reflexões mais profundas.

A percepção, como processo, permanece particular e complexo. Contrariando Dondis (1997), foi possível observar que ainda não é possível estabelecer um processo de leitura e compreensão das imagens voltadas a sua produção pautada na redução de imagens a conjuntos de elementos destituídos de contexto.

Por meio do trajeto traçado durante o processo de pesquisa foi possível perceber, dentro do grupo estudado, que aspectos culturais influenciam diretamente a percepção do indivíduo e não obrigatoriamente as teorias visuais serão observadas nas preferências visuais. Fatores como personalidade e experiência de vida têm relação com os processos perceptivos, atuando na visualidade. Neste sentido, Arnheim (2013) apresenta um discurso mais conciso e válido ao contexto atual, enquanto Dondis (1997) apresenta ideias insuficientes às produções imagéticas contemporâneas. 
O processo de Vygotsky (2010) acerca da formação do indivíduo por meio da cultura e das inter-relações sociais tem se mostrado bastante eficaz enquanto mecanismo de avaliação do comportamento e dos processos inteligíveis do indivíduo. Sua teoria visionária sobre a cultura como elemento transformador e das adaptações particulares dos inputs externos foi decisiva nos processos de análise e interpretação das escolhas perceptíveis da população.

Como passos futuros para esta pesquisa, sente-se a necessidade, após a conclusão do processo, da repetição do experimento com outros indivíduos com diferentes graus de aproximação com as teorias visuais a fim de obter mais parâmetros de análise dessas influências.

Compreender a linguagem visual e os processos cognitivos significam, primeiramente, compreender mais sobre o indivíduo e sobre o macrocontexto em que este encontra-se inserido. São suas experiências, conhecimentos adquiridos e reflexões sobre o mundo os grandes formadores dos processos inteligíveis e das inter-relações sociais. 


\section{REFERÊNCIAS}

ACAUAN, E. M. O.; PERSICHETTI, S. A estética de Sebastião Salgado. 2010. Trabalho de conclusão de curso (Especialização em Fotografia) - Universidade Estadual de Londrina, Londrina, 2010.

ACAUAN, E. M. O. SOBRAL, João E. C. As percepções do olhar: uma análise da linguagem fotográfica em crianças. 2015. Dissertação (Mestrado em Design) - Univille, Joinville, 2015.

ARNHEIM, R. Arte e percepção visual: uma psicologia da visão criadora. Trad. Ivonne Terezinha de Faria. São Paulo: Pioneira Thomson Learning, 2013.

BORGES, M. E. L. História \& fotografia. Autêntica, 2013.

CASTORINA, J. A. $O$ debate Piaget-Vygotsky: a busca de um critério para sua avaliação. São Paulo: Ática, 2008.

COSTA, J. El linguaje fotográfico. Madrid: Ibérico Europeia, 1977.

DONDIS, D. Sintaxe da Linguagem Visual. Trad. Jefferson Luiz Camargo. 2. ed. São Paulo: Martins Fontes, 1997.

DUBOIS, P. $\mathbf{O}$ ato fotográfico e outros ensaios. Campinas: Papirus Editora, 1993.

GIL, A. C. Como elaborar projetos de pesquisa. 5. ed. São Paulo: Atlas, 2010.

KRAUSS, R. $O$ fotográfico. Trad. Anne Marie Davée. 2. ed. Barcelona: Gustavo Gili, 2002.

PIAGET, J. Éstudes Socologiques. Genéve: Droz, 1965. 
ROUILLÉ, A. A fotografia: entre documento e arte contemporânea. Trad. Constancia Egrejas. São Paulo: Senac São Paulo, 2009.

SACKS, O. W. O homem que confundiu sua mulher com um chapéu e outras histórias clínicas. São Paulo: Companhia das Letras, 2005. SONTAG, Susan. Diante da dor dos outros. São Paulo: Companhia das Letras, 2003.

TAILLE, Y. OLIVEIRA, M. K.; DANTAS, H. Piaget, Vygotsky, Wallon: teorias psicogenéticas em discussão. São Paulo: Summus Editorial, 1992.

VYGOTSKY, L. S. Formação social da mente. Trad. José Cipolla Neto; Luis Silveira Menna Barreto; Solange Castro Afeche. 4. ed. São Paulo: Martins Fontes, 2010.

. Pensamento e linguagem. São Paulo: Martins Fontes, 1998. 